\title{
Efficacy of Whole-Lung Lavage in Pulmonary Alveolar Proteinosis: A Multicenter International Study of GELF
}

\author{
Pierre Gay ${ }^{a}$ Benoit Wallaert ${ }^{b}$ Stefan Nowak ${ }^{c}$ Jonas Yserbyt ${ }^{d}$ \\ Stavros Anevlavis ${ }^{\mathrm{e}}$ Christophe Hermant ${ }^{f} \quad$ Alban Lovis $^{g} \quad$ Olivier Menard $^{\text {h }}$ \\ Bernard Maitre $^{i}$ Thomas Vandemoortele $^{j}$ Hervé Dutau $^{k} \quad$ Amandine Briault $^{l}$ \\ Arnaud Bourdin $^{c}$ Jean-Michel Vergnon ${ }^{a}$ Marios E. Froudarakis ${ }^{a}$ e \\ Groupe d'Endoscopie Thoracique de Langue Française
}

Departments of Pulmonology, University Hospitals of a Saint-Étienne, ${ }^{b}$ Lille, and ${ }^{\mathrm{c} M o n t p e l l i e r, ~ F r a n c e ; ~}{ }^{\mathrm{d}}$ Leuven, Belgium; ${ }^{\mathrm{e}}$ Alexandroupolis, Greece; ${ }^{\mathrm{f}}$ Toulouse, France; ${ }^{9}$ Lausanne, Switzerland; ${ }^{\mathrm{h}}$ Nancy and ${ }^{\mathrm{i}}$ Créteil, France;

jMontréal, QC, Canada; and kMarseille and 'Grenoble, France

\section{Keywords}

Whole-lung lavage $\cdot$ Total lung lavage $\cdot$ Lung lavage .

Pulmonary alveolar proteinosis · Treatment

\begin{abstract}
Background: New therapies have emerged in the treatment of pulmonary alveolar proteinosis (PAP) and, therefore, there is a real need to evaluate the efficacy of whole-lung lavage (WLL) in this rare disease. Objectives: The aim of this study was to assess the efficacy of WLL in patients with PAP. Methods: We included 33 patients from 12 centers, which are members of the French-Speaking Thoracic Endoscopy Group, for analysis. Data collection concerned patients and disease characteristics, pulmonary function tests (PFTs) and technical information on the procedure. Results: The median age of the patients was 44 years (range 13-77). There were $23(71.9 \%)$ patients with respiratory insufficiency at presentation. All patients underwent WLL by general anesthesia and selective lung ventilation, except 1 who under-
\end{abstract}

(c) 2017 S. Karger AG, Basel went awake flexible bronchoscopy. We noted differences in the technique, as 12 (36.36\%) patients had percussion during the procedure and only $4(12.1 \%)$ patients underwent 2-lung lavage during 1 anesthesia. A median of $12 \mathrm{~L}$ was used to perform WLL (1.0-40 L). Complications occurred in 11 (33.3\%) patients, and 18 (56.25\%) of them relapsed in a median period of 16.9 months. No significant changes were found in any PFT parameters studied, except for $\mathrm{PaO}_{2}$, which was significantly improved by $6.375 \mathrm{~mm} \mathrm{Hg}(p=0.0213)$ after the procedure compared to before. Conclusions: Although the application of the WLL technique was variable, overall, it significantly improved patients' short-term respiratory condition by improving $\mathrm{PaO}_{2}$. However, a long-term effect needs to be confirmed, as many of our patients relapsed.

(c) 2017 S. Karger AG, Basel

This study has been accepted as an oral presentation at the recent World Congress for Bronchology and Interventional Pulmonology (WCBIP) 2016 (Florence, Italy) and at the European Respiratory Society (ERS) Congress 2016 (London, UK).
Marios E. Froudarakis

Service de Pneumologie et d'Oncologie Thoracique

Hôpital Nord - CHU Saint-Étienne

FR-42055 Saint-Étienne Cedex 2 (France)

E-Mail marfroud@gmail.com 


\section{Introduction}

Pulmonary alveolar proteinosis (PAP) is a rare lung disease that was first described by Rosen in 1958 [1]. PAP is characterized by the accumulation of proteins and lipids of the surfactant in the alveolar duct, which are stained positively by periodic acid-Schiff, resulting in impairment of gas exchange [1-3]. Patients commonly present with cough and dyspnea [1]. The diagnosis is based on the typical findings of the "crazy-paving" pattern on chest high-resolution computed tomography (HRCT) and the "milky" fluid of bronchoalveolar lavage (BAL) $[4,5]$. Transbronchial, transthoracic or surgical biopsy confirms the presence of proteins and lipids stained by periodic acid-Schiff [6]. Three main categories of PAP have been defined depending on the etiology: autoimmune (or primary, or idiopathic), secondary and genetic [3]. Adult forms are mostly autoimmune, with anti-granulocyte macrophage colony-stimulating factor (GM-CSF) antibodies, and/or secondary to toxic inhalation or hematological disorders, without anti-GM-CSF antibodies [3].

In recent years, novel therapies have emerged, such as inhaled GM-CSF [7], plasmapheresis [8] and rituximab [9], with the aim to be efficacious in this patient population. Yet, these treatments are costly and have not been fully evaluated in a prospective way. The classic treatment of PAP is whole-lung lavage (WLL) [10], which was first described in 1963 [11]. WLL is performed with at least 10 L per lung of normal saline, under general anesthesia and selective ventilation [12]. The technique is very demanding in both its application and post-procedural patient management, and therefore, it is only applied in experienced centers. Although widely considered as the standard of care, the WLL procedure, its specific indications and the outcome criteria have not been standardized among centers, and there is still a significant variability in the technique between centers. As a consequence, few studies exist reporting results from patients undergoing WLL. Thus, the aim of our study was to evaluate the efficacy and complications of classic treatment of WLL in a cohort of patients with PAP from experienced centers of the Groupe d'Endoscopie Thoracique de Langue Française (GELF French-Speaking Thoracic Endoscopy Group).

\section{Methods}

\section{Study Design}

This study is based on a survey submitted to all GELF members. Twelve centers treating adult patients participated in this study (Fig. 1). The survey was approved by all local internal re-
Table 1. Patients' characteristics $(n=33)$

$\begin{array}{lc}\text { Gender } & \\ \text { Male } & 23(69.7) \\ \text { Female } & 10(30.3) \\ \text { Median age (range), years } & 44(13-77) \\ \text { Type of PAP } & \\ \quad \text { Primary } & 27(81.8) \\ \text { Secondary } & 6(18.2) \\ \text { BAL characteristics } & \\ \text { Typical } & 28(84.8) \\ \text { Atypical } & 5(15.1) \\ \text { CT characteristics } & \\ \text { Typical } & 31(93.9) \\ \text { Atypical } & 2(6.1) \\ \text { GM-CSF autoantibodies receptor } & \\ \text { Positive } & 25(80.6) \\ \text { Negative } & 2(6.5) \\ \text { Endoscopic biopsies } & \\ \text { Positive } & 9(29) \\ \text { Negative } & 4(12.9) \\ \text { Surgical biopsies } & 5(16.1) \\ \text { Arguments motivating lavage } & \\ \text { Dyspnea } & 29(90.6) \\ \text { Respiratory insufficiency at rest } & 23(71.9) \\ \text { First-line treatment } & 22(68.8) \\ \text { GM-CSF treatment failure } & 5(15.2) \\ & \end{array}$

Values are $n(\%)$ unless otherwise indicated. PAP, pulmonary alveolar proteinosis; BAL, bronchoalveolar lavage; CT, computed tomography; GM-CSF, granulocyte macrophage colony-stimulating factor. ${ }^{\text {a }} 3$, hematological malignancies; 2 , professional exposure; 1 , infection.

view boards. Patients' inclusion criteria were confirmation of PAP and therapeutic lung lavage. There were no exclusion criteria at this point. Criteria for WLL efficacy measurement to determine the patients' outcomes, related to the procedure only, were (1) "excellent" if the patient had a complete symptom relief and normal radiological and pulmonary function test (PFT) features; (2) "improved" if clinical, radiological and PFT improvement occurred; (3) "stable" if there was no change and (4) "worse" if the patient was worse or in case of a serious complication or death.

Also, physicians who included patients in the study were asked to globally evaluate the efficacy of the procedure by answering the following questions:

1 Was the WLL a routine procedure for them?

2 Do they consider WLL the first treatment approach in PAP?

3 Do they consider WLL efficient?

4 Do they consider WLL superior to other treatments?

5 Are they willing to abandon WLL for the benefit of other treatments?

Possible answers were (1) "yes," (2) "no," (3) "don't know - need further evaluation" or (4) "other - please specify." 


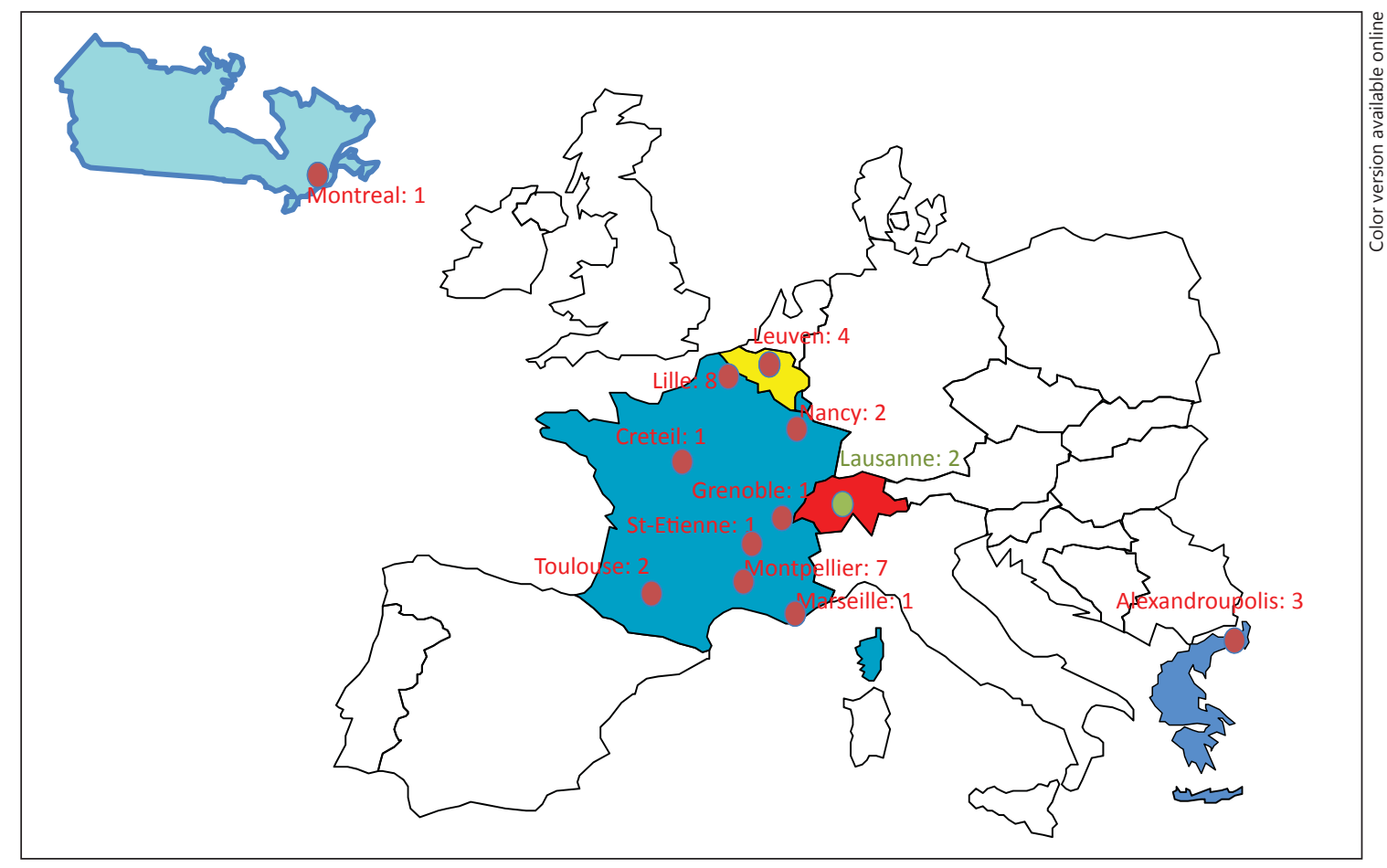

Fig. 1. Participating centers with number of included patients.

\section{Patients}

Overall, 33 patients were included. Data collected were patients' demographics, their PAP forms, methods for diagnosis, PFTs at diagnosis and after WLL, details on the procedure, complications and outcomes.

\section{Statistical Analysis}

Descriptive statistics were used to study patients' characteristics. Data are expressed as percentage of the total study population, median (range) or mean \pm standard deviation when appropriate. The Student $t$ test was performed to compare groups. Simple regression analysis was also performed. Results were considered statistically significant at $p<0.05$. Data analysis was performed with StatView ${ }^{\mathrm{TM}}$ software (Abacus Concepts Inc., Berkeley, CA, USA).

\section{Results}

Patients' characteristics and PAP features are shown in Table 1 . The median age was 44 years (range 13-77) with a male predominance $(69.7 \%)$. Only 5 patients $(16.1 \%)$ underwent a surgical biopsy for PAP diagnosis when BAL and transbronchial biopsy were not sufficient to draw any conclusions (Fig. 2). The majority of patients (81.1\%) had primary PAP. Patients' major symptom at presentation was dyspnea (29-90.8\%), associated with respiratory in- sufficiency (Table 1) and motivating WLL. Before performing WLL, 23 (71.9\%) patients were hypoxic at rest and $5(15.2 \%)$ were first treated by GM-CSF, which led to WLL in case of treatment failure.

Regarding the procedure, the median period between diagnosis of PAP and WLL was 7 months (range 0-60). All patients with general anesthesia $(n=32,95 \%)$ had a selective intubation, but only $12(36.4 \%)$ had thoracic percussion. Only 4 (12.1\%) patients had both lungs treated in the same setting. In only $6(18.2 \%)$ patients who underwent WLL a flexible bronchoscope was used, and among these 6 patients only 1 (a female child) had local anesthesia (Table 2). The duration of the procedure itself was $150 \mathrm{~min}$ (range 35-270), and the duration of anesthesia was $197.5 \mathrm{~min}$ (range 90-300) (Table 2). The volume of saline water used was variable ranging from 1 to $40 \mathrm{~L}$ (Table 2; Fig. 3). After the procedure (Table 2), 14 (42.4\%) patients returned to a medical ward directly and 19 $(57.6 \%)$ to an intensive care unit with a median stay of 2 days (range 0.5-28).

Seventeen (51.5\%) patients had a single WLL considered as enough to treat PAP. A second lavage was done in 13 patients, and multiple lavages were done in 3 patients (Table 3). The efficacy of WLL (Table 3) was rated as "ex- 

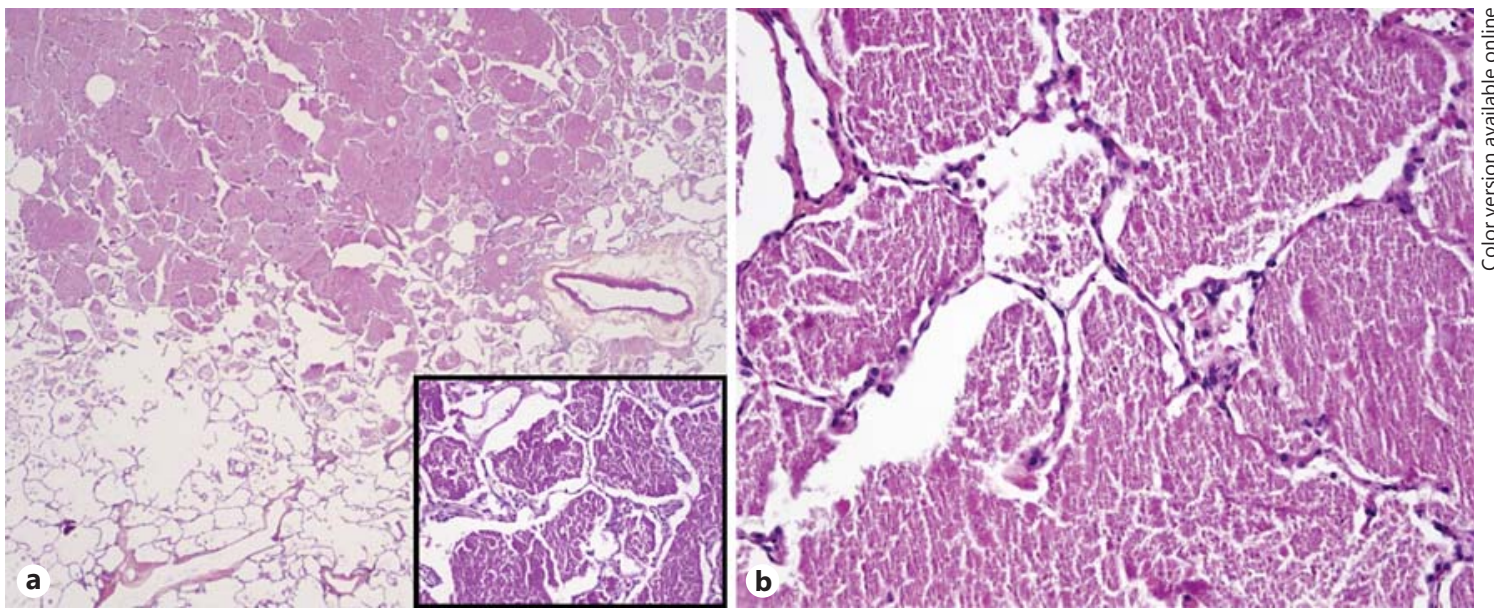

Fig. 2. a Structurally normal alveoli are filled with an eosinophilic material (HES, $\times 25)$. b At a higher magnification, this is amorphous granular material (HES, $\times 200$ ) which stains positive for periodic acid-Schiff (inset $\times 200)$. Courtesy of Dr. Georgia Karpathiou, Department of Pathology, University Hospital of Saint-Étienne, SaintÉtienne, France.

Table 2. Procedure modalities

\begin{tabular}{lc}
\hline Anesthesia & \\
$\quad$ General & $32(97)$ \\
Local & $1(3)$ \\
Decubitus & \\
$\quad$ Dorsal & $23(69.7)$ \\
$\quad$ Lateral & $10(30.3)$ \\
Lavage location & $14(42.4)$ \\
Left lung & $15(45.5)$ \\
Right lung & $4(12.1)$ \\
Both & \\
Technical procedure & $32(96.8)$ \\
$\quad$ Selective intubation & $12(36.4)$ \\
Thorax percussion & $6(18.2)$ \\
Flexible endoscopy & \\
Following procedure & $14(42.4)$ \\
Pulmonary ward & $19(57.6)$ \\
Intensive care & $12(1-40)$ \\
Median lavage modalities (range) & $150(35-270)$ \\
$\quad$ Normal saline per procedure, L & $197.5(90-300)$ \\
Procedure time, min & $2(0.5-28)$ \\
Anesthesia time, min & \\
Intensive care, days & \\
\hline Values are $n$ (\%) unless otherwise indicated. & \\
\hline
\end{tabular}

cellent" in $6(18.2 \%)$ patients, as "improved" in $11(33.3 \%)$, as "stable" in $7(21.2 \%)$ and as "worse" in $9(27.3 \%)$.

Procedure complications (Table 3) occurred in 11 (33.3\%) patients. The most frequent complication was a

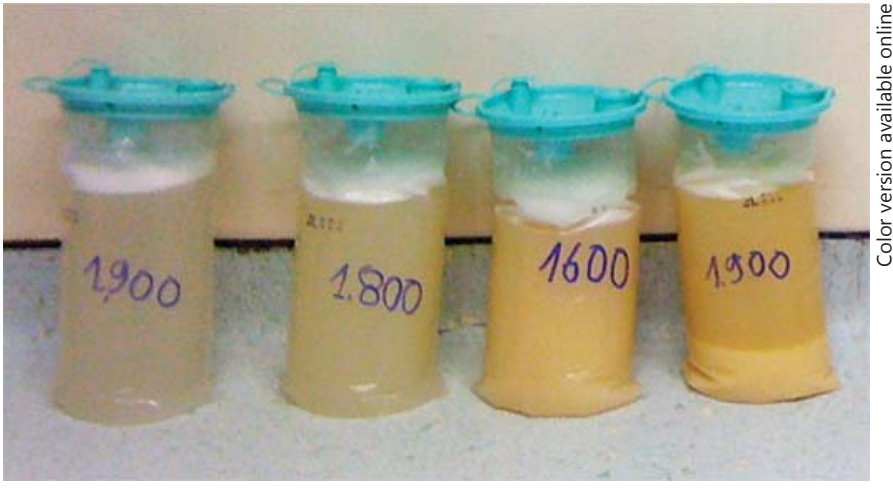

Fig. 3. Fluid extracted during whole-lung lavage from a patient with alveolar proteinosis. Note the clarity modifications according to the time of the lavage: the latest seems quite clear, while the initial one has split into 2 layers (the picture was provided by M.E.F.).

drop in oxygen saturation in $5(12.1 \%)$ patients. Two patients died after WLL: a 70-year-old man who had been diagnosed with a secondary PAP due to a myelodysplastic syndrome and a 63-year-old female with severe respiratory insufficiency in whom no improvement was noted after WLL and who died 4 weeks later.

After the procedure, we noted a significant overall improvement in $\mathrm{PaO}_{2}$ of $6.375 \mathrm{~mm} \mathrm{Hg}(p=0.02$, interquartile range 1.038-11.712; Table 4; Fig. 4). Also, there was a trend towards a better KCO of $4.238 \%$ ( $p=0.19$; interquar- 


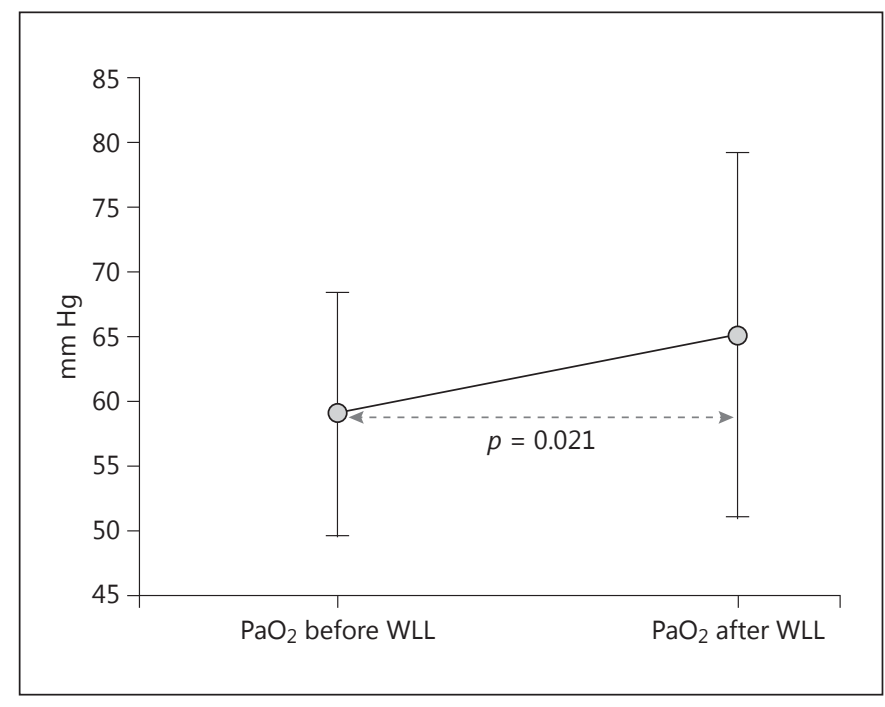

Fig. 4. $\mathrm{PaO}_{2}$ before and after whole-lung lavage (WLL). Values are expressed as mean $\mathrm{mm} \mathrm{Hg}$ and standard deviations as error bars.

tile range -2.34 to 10.82$)$. When we performed simple regression analysis between the difference $(\Delta)$ of postprocedure $\mathrm{PaO}_{2}$ - pre-procedure $\mathrm{PaO}_{2}$ and $\Delta$ post-procedure $\mathrm{KCO}$ - pre-procedure KCO, these 2 parameters were significantly positively related $\left(p=0.0012, r^{2}=0.68\right.$; Fig. 5).

Follow-up was available in all cases but one. Overall, $19(57.6 \%)$ patients relapsed, and $9(27.3 \%)$ had a new WLL after relapsing. Treatment of relapsed patients is shown in Table 5.

Participating physicians' answers to the survey submitted are shown in Table 6. Overall, we noted that most of the 12 physicians believe that WLL is efficient and are not ready to abandon this approach for the benefit of other treatments.

\section{Discussion}

WLL is performed by few experienced centers worldwide as PAP is a rare disease, and thus few studies report data on this procedure. The evaluation of WLL as an efficient method of treatment in PAP is an absolute necessity as in the recent years, novel therapies have emerged, such as GM-CSF [7, 13], plasmapheresis [8] and rituximab [9]. Our study reports data from expert centers on interventional pulmonology aiming to evaluate the efficacy of the technique as well as complications and differ-
Table 3. Treatment, efficacy and complications

$\begin{array}{lc}\text { Treatment } & \\ \text { Single lavage } & 17(51.5) \\ \text { Second lavage } & 13(39.4) \\ \text { Multiple lavages } & 3(9.1) \\ \text { Efficacy } & \\ \text { Excellent } & 6(18.2) \\ \text { Improved } & 11(33.3) \\ \text { Stable } & 7(21.2) \\ \text { Insufficient } & 9(27.3) \\ \text { Complications } & \\ \text { Desaturation } & 5(12.1) \\ \text { Headache/fever } & 1(3) \\ \text { Hemodynamic collapses } & 1(3) \\ \text { Subcutaneous emphysema } & 1(3) \\ \text { Pneumonitis } & 1(3) \\ \text { Cardiogenic pulmonary edema } & 1(3) \\ \text { Intubation dislocation } & 1(3) \\ \text { Prolonged intubation } & 1(3) \\ \text { Death } & 2(6)\end{array}$

Values are $n(\%)$.

Table 4. Pulmonary function tests before and after lavage

\begin{tabular}{|c|c|c|c|}
\hline Parameters & Before lavage & After lavage & $p$ \\
\hline $\mathrm{FEV}_{1}$ & $75.5 \pm 22.3$ & $81.0 \pm 24.0$ & 0.1 \\
\hline $\mathrm{FVC}$ & $78.2 \pm 17.7$ & $78.6 \pm 24.0$ & 0.1 \\
\hline Total lung capacity & $78.0 \pm 19.9$ & $72.3 \pm 21.4$ & 0.41 \\
\hline $\mathrm{PaO}_{2}$ & $59.1 \pm 9.5$ & $65.2 \pm 14.2$ & 0.021 \\
\hline $\mathrm{PaCO}_{2}$ & $34.6 \pm 3.8$ & $35.2 \pm 3.5$ & 0.44 \\
\hline $\mathrm{KCO}$ & $59.2 \pm 11.2$ & $65.5 \pm 15.0$ & 0.19 \\
\hline
\end{tabular}

$\mathrm{FEV}_{1}, \mathrm{FVC}$, total lung capacity and KCO mean values are expressed as percentage of the predicted values \pm standard deviations, while $\mathrm{PaO}_{2}$ and $\mathrm{PaCO}_{2}$ are expressed as $\mathrm{mm} \mathrm{Hg} \pm$ standard deviations.

ences in the application. Furthermore, our patients presented, in most of the cases (72\%), with respiratory insufficiency at rest.

Important data reported in our study were the long duration of the procedure as well as the duration of anesthesia. The technique varies between our centers: only $36.4 \%$ used percussion during the procedure when it seemed to be recommended $[14,15]$, some centers used flexible bronchoscopy instead of selective intubation, and in 1 case flexible bronchoscopy under local anesthesia was used [16]. Flexible bronchoscopy is indicated when a patient cannot tolerate general anesthesia or presents 
Fig. 5. Simple regression analysis between $\Delta \mathrm{PaO}_{2}$ and $\Delta \mathrm{KCO}(p=0.0012)$ (values of $\Delta \mathrm{PaO}_{2}$ are expressed as $\mathrm{mmHg}$ and values of $\Delta \mathrm{KCO}$ as percentage of the predicted).

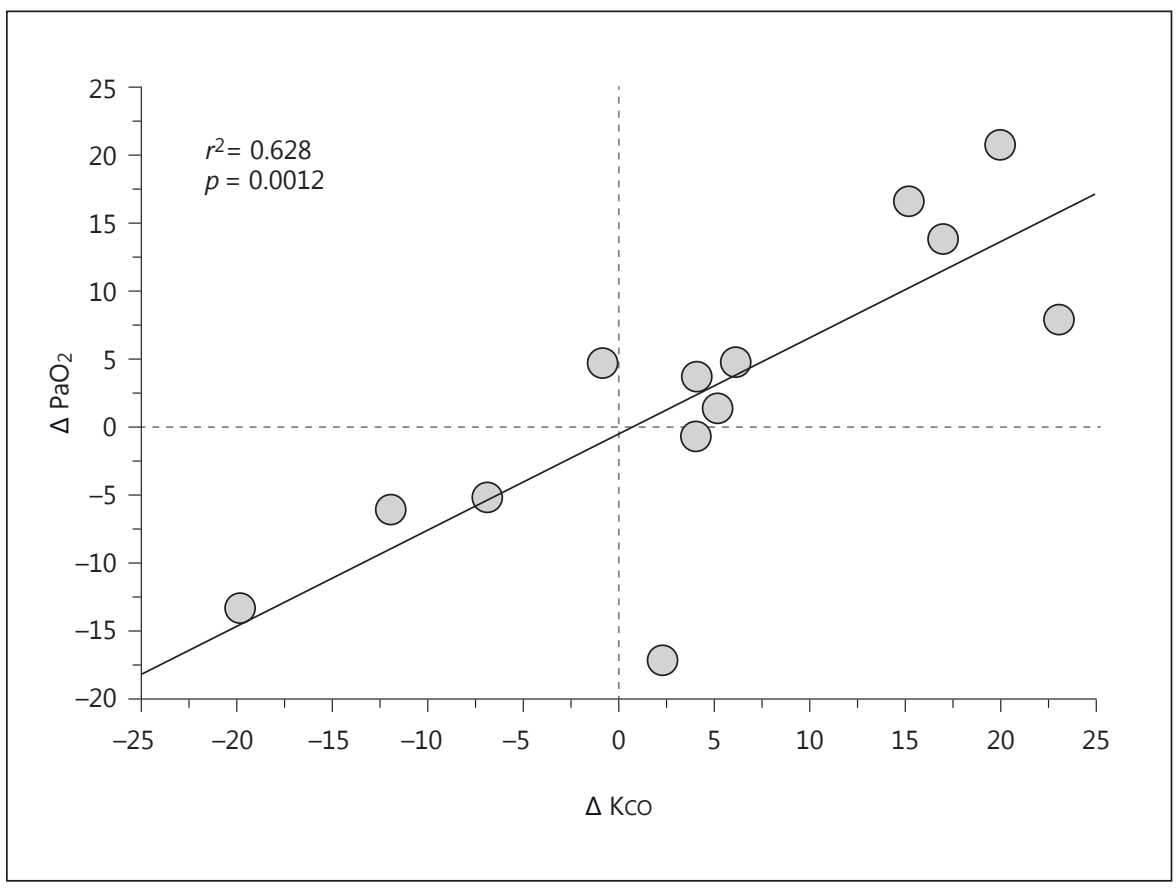

Table 5. Relapse and treatment

\begin{tabular}{ll}
\hline Relapse & $19(57.6)$ \\
Relapse treatment & \\
Lavage & $9(27.3)$ \\
Inhaled GM-CSF only & $3(9.1)$ \\
Subcutaneous GM-CSF only & $3(9.1)$ \\
Rituximab only & $2(6.1)$ \\
Lavage + rituximab & $1(3)$ \\
Lavage + inhaled GM-CSF & $1(3)$ \\
Corticosteroids & $1(3)$ \\
\hline
\end{tabular}

Values are $n(\%)$. GM-CSF, granulocyte macrophage colonystimulating factor.

with less severe disease, or in pediatric cases [16-18]. This procedure is generally safe, yet less effective because of the use of a small lavage volume. Variations between the participating centers exist also in the patients' post-procedural management. In the majority of centers, patients stayed for a median of 2 days in intensive care after the procedure, while in other centers, patients returned to the pulmonary ward immediately. A possible explanation is the disease severity and patients' condition related to PAP, but also the procedure modalities, such as single or double lung lavage [6].

Whole-Lung Lavage in Pulmonary Alveolar Proteinosis
In a recent international multicenter survey involving 20 centers worldwide $[19,20]$, general anesthesia was used almost universally in adults with a double-lumen tracheal tube in 2 consecutive sessions (1 lung per session), with an interval of 1-2 weeks between WLL procedures observed by $50 \%$ of centers. The amount of fluid used to perform the WLL varied also greatly $(800 \mathrm{~mL}$ of warm saline on average), with great variability of the total volume used per lung, with a range from 5 to $40 \mathrm{~L}$. Most (14 of 20) centers used chest percussion to emulsify the PAP sediment to improve therapeutic efficiency. However, the method and timing varied greatly, as in our series. Ten centers (50\%) used manual chest percussion and $4(20 \%)$ used mechanical percussion. The authors finally concluded that WLL is safe and effective as a therapy for PAP. This study represents a first step in developing an evidence-based, best-practice approach to standardize WLL therapy for PAP $[19,20]$.

In our series, WLL was immediately effective in 17 (51.5\%) patients, as only 1 WLL was sufficient to improve their condition. This is the case in most of the series, although the rates are higher than ours. This difference may be explained by the variability of the disease severity of the included patients in the different series, as well as by the fact that many of our patients had undergone other therapies previous to WLL, with secondary relapse [21]. A second lavage is common to complete the initial thera- 
Table 6. Physicians' answers concerning WLL according to the questions of the survey $(n=12)$

\begin{tabular}{|c|c|c|c|c|c|}
\hline Answers & $\begin{array}{l}\text { Routine } \\
\text { procedure }\end{array}$ & $\begin{array}{l}\text { First-line } \\
\text { treatment }\end{array}$ & $\begin{array}{l}\text { Efficient } \\
\text { treatment }\end{array}$ & $\begin{array}{l}\text { Superior treatment } \\
\text { to others }\end{array}$ & $\begin{array}{l}\text { Willing to abandon } \\
\text { WLL }\end{array}$ \\
\hline Yes & $12(100)$ & $10(83.3)$ & $10(83.3)$ & $8(66.6)$ & $2(6.6)$ \\
\hline No & & $1(3.3)$ & $1(3.3)$ & $2(16.6)$ & $10(83.3)$ \\
\hline Needs evaluation & & $1(3.3)$ & $1(3.3)$ & $2(16.6)$ & \\
\hline
\end{tabular}

Values are $n(\%)$. WLL, whole-lung lavage.

peutic approach $[15,22,23]$, as in our series where 13 (39.4\%) patients underwent a second lavage, while another 3 (9\%) had multiple WLL. Seymour and Presneill [6] in their analysis showed the effectiveness of WLL to improve survival in this patient population: in a group of 146 patients, the mean rate of survival at 5 years was $94 \%$ with lavage as compared to $85 \%$ without lavage, and this difference was statistically significant $(p=0.04)$.

An overall improvement in $\mathrm{PaO}_{2}$ was noted in our patient population after WLL, resulting in an improved condition. No other PFT parameter was improved significantly in our series, although there was a trend towards a significant improvement in KCO. This correlation between $\mathrm{PaO}_{2}$ change $\left(\Delta \mathrm{PaO}_{2}\right)$ and $\mathrm{KCO}$ change $(\Delta \mathrm{KCO})$ in our series was confirmed by the simple regression analysis (Fig. 3). Lung function improvement after WLL has been reported previously $[6,21,22]$. In a Chinese cohort [21], most parameters of PFTs, such as $\mathrm{FEV}_{1}, \mathrm{FVC}, \mathrm{PaO}_{2}$ and $\mathrm{KCO}$, improved after WLL, confirming the data of Seymour and Presneill [6]. Again, variability between the different series in the improvement of PFTs might be due to the time point of data collection and the severity of the disease, as many patients presenting with severe disease are in fact unable to perform PFTs.

In our study, the median age of the patients was 44 years, confirming that PAP occurs in a young age group, supporting the same finding noted by most authors reporting data from Caucasian populations $[6,21,22]$. However, in Asian populations a controversy exists on whether PAP patients are young [23] or old [24]. The reasons for this discrepancy are unclear but might be associated with patient selection, ethnic differences or simply the heterogeneity of the disease itself. Also, $81.8 \%$ of patients had primary PAP $[1,2]$, and $84.8 \%$ presented with a typical BAL fluid sufficient for diagnosis as in other Caucasian series [1], compared to only $58.7 \%$ in a Japanese cohort [24]. In our cohort, only 2 HRCT were atypical, and all our patients with primary PAP had positive
GM-CSF antibodies, showing that the combination of HRCT, BAL and GM-CSF antibodies is sufficient to diagnose primitive PAP. Another option for a minimally invasive diagnosis of PAP is transbronchial biopsy, especially in children $[16,17]$. However, $16 \%$ of our patients underwent surgical biopsy to confirm the diagnosis.

Although spontaneous remission may occur in some patients, most of them require therapy because respiratory insufficiency is present, expressed by dyspnea [22, 23 ]. Indeed, dyspnea was present in $90 \%$ of our cases and was associated with hypoxemia at rest in $72 \%$ of our patients, resulting in therapeutic intervention [22]. Concerning the procedure itself, we had a 7-month median interval between diagnosis and first WLL, while in the literature the average is 2 months [6]. This difference was due to the fact that some of our patients were referred for lavage after having simply been followed up or after failure of their initial treatment, such as GM-CSF [6].

Overall, $57 \%$ of patients presented with secondary relapse in our series. This high rate of relapses is well known $[2,6]$. The mechanism is not fully understood, yet the accumulation of surfactant according to disease severity and cause is a determining factor [2]. The management of relapses in our study varied between the centers; some treated relapses with multiple lavages, while others treated them with newer therapies, such as rituximab [9] or inhaled GM-CSF [7] associated with lavage or not. Yet, no studies have systematically addressed the effect of combination therapy in PAP patients. Uncommonly, corticoids have been used with no results [25] as was the case in 1 of our patients.

Either inhaled [7] or subcutaneous [13] GM-CSF has been suggested alternatively. Indeed, a recent prospective study in 39 patients with autoimmune PAP showed efficacy in $62 \%$ of the cases [7]. A meta-analysis of GM-CSF observational studies [26] suggested a cumulative response rate that was slightly lower (58\%) with GM-CSF therapy in autoimmune PAP, with a better response via 
the inhaled route than via the subcutaneous route (76 vs. $48 \%$ ) [26]. However, $30 \%$ of the GM-CSF responders relapsed during follow-up, and the number of relapses was less in the inhaled than in the subcutaneous group, probably because of the direct local deposition in the alveolar space, which is the putative site of GM-CSF signal disruption [26]. Furthermore, the inhaled GM-CSF may prevent long-term myelosuppression encountered with the subcutaneous route $[14,26]$, especially in young patients [16]. This therapy alone is indicated in mild to moderate PAP [14]; however, no clinical or biological marker exists today to predict response to GM-CSF and to select patients that could benefit from GM-CSF therapy [3]. Indeed, the concentration of anti-GM-CSF antibodies and evolution under therapy do not seem to be associated with response [3].

Rituximab, a monoclonal antibody directed against the CD20 antigen of B-lymphocytes, may also be an alternative therapy, as it has shown activity in an open-label study [9]. In 10 patients with PAP, improvements were noted in $\mathrm{PaO}_{2}$, total lung capacity, HRCT and dyspnea [9]. However, following rituximab therapy, high relapse rates have also been reported [14]. Plasmapheresis might be another option, but it has been tested in a few cases only $[8,27]$. However, this technique may lead to serious complications, such as life-threatening sepsis [27], while non-response may lead to WLL [28].

Complications in our study occurred in $33 \%$ of patients overall, with an immediate drop of $\mathrm{SaO}_{2}$ during the procedure in $12.1 \%$ of patients as in other studies [15]. In 1 case, a loss of bronchial isolation was reported with no serious consequences (procedure prolongation) [15], and in another case a methicillin-resistant Staphylococcus aureus pneumonia was noted but successfully treated. One patient reported headache and fever without evidence of infection, probably due to anesthesia. Unexplained subcutaneous emphysema occurred in 1 case; it was not associated with pneumothorax [15]. Finally, another patient had a moderate pulmonary edema appearing a few days after the procedure. The origin of this edema is not fully understood, yet the cause might be cardiogenic (due to the roughness of the procedure) or non-cardiogenic (local inflammatory reaction) due to the procedure itself [29]. We counted 2 deaths; one was related to the severity of the disease at presentation (PAP-associated acute respiratory distress syndrome), where WLL was obviously not effective, and the other was secondary to a myeloid disorder, which is the most common association [30].

Interestingly, most of the physicians participating in the study considered that there is a therapeutic benefit of
WLL in patients with PAP. This is the first study in the literature reporting results from a physicians' survey. Our first question concerning the routine practice of WLL (Table 6) was intended to check whether, indeed, all centers were "experts" in performing the procedure, in order to have a homogenous sample. On the other hand, this positive opinion may also reflect a selection bias among expert endoscopists, though a necessary one. Indeed, PAP should always be managed in a center with experience and knowledge and which has a track record on the safety and effectiveness of the procedure [31]. The participating physicians do not consider changing their opinion about the utility of WLL as a first-line treatment and, therefore, are not ready to abandon this procedure for another therapy. This point of view is probably related to many factors: firstly, the patients treated by those centers have severe disease with respiratory insufficiency; secondly, physicians performing WLL are thoracic endoscopy experts, and thirdly, no other therapeutic alternative has proven to be clearly more efficient in this patient population with severe PAP [14].

To conclude, our study shows that in patients with severe PAP, WLL still has a role to play, although the application of the technique varies between the different participating expert centers. However, a long-term effect needs to be confirmed, as many of our patients relapsed.

\section{Author Contributions}

M.E.F. conceived the study; M.E.F., P.G. and J.-M.V. developed the questionnaire and organized the survey; the authors from each center collected patients' data and filled in the questionnaire; P.G. collected all data; M.E.F. performed the statistical analysis; and P.G., J.-M.V. and M.E.F. drafted the manuscript that has been reviewed and approved by all authors.

\section{Financial Disclosure and Conflicts of Interest}

The authors state that there are no conflicts and no funding sources to disclose in relation to this article.
References
1 Trapnell BC, Whitsett JA, Nakata K: Pulmo- nary alveolar proteinosis. N Engl J Med 2003; 349:2527-2539. JP, Meunier C, Letheulle J, Chiforeanu D, Laine-Caroff C, Desrues B, Delaval P: Pulmo- nary alveolar proteinosis. Rev Mal Respir
-2 Jouneau S, Kerjouan M, Briens E, Lenormand 2014;31:975-991.

Whole-Lung Lavage in Pulmonary Alveolar Proteinosis 
3 Borie R, Danel C, Debray MP, Taille C, Dombret MC, Aubier M, Epaud R, Crestani B: Pulmonary alveolar proteinosis. Eur Respir Rev 2011;20:98-107.

-4 Briens E, Delaval P, Mairesse MP, Valeyre D, Wallaert B, Lazor R, Cordier JF: Pulmonary alveolar proteinosis. Rev Mal Respir 2002;19: 166-182.

5 Wang BM, Stern EJ, Schmidt RA, Pierson DJ: Diagnosing pulmonary alveolar proteinosis. A review and an update. Chest 1997;111:460466.

6 Seymour JF, Presneill JJ: Pulmonary alveolar proteinosis: progress in the first 44 years. Am J Respir Crit Care Med 2002;166:215-235.

$\checkmark 7$ Tazawa R, Trapnell BC, Inoue Y, Arai T, Takada T, Nasuhara Y, Hizawa N, Kasahara Y, Tatsumi K, Hojo M, Ishii H, Yokoba M, Tanaka N, Yamaguchi E, Eda R, Tsuchihashi Y, Morimoto K, Akira M, Terada M, Otsuka J, Ebina M, Kaneko C, Nukiwa T, Krischer JP, Akazawa K, Nakata K: Inhaled granulocyte/ macrophage-colony stimulating factor as therapy for pulmonary alveolar proteinosis. Am J Respir Crit Care Med 2010;181:13451354.

-8 Luisetti M, Rodi G, Perotti C, Campo I, Mariani F, Pozzi E, Trapnell BC: Plasmapheresis for treatment of pulmonary alveolar proteinosis. Eur Respir J 2009;33:1220-1222.

\9 Kavuru MS, Malur A, Marshall I, Barna BP, Meziane M, Huizar I, Dalrymple H, Karnekar R, Thomassen MJ: An open-label trial of rituximab therapy in pulmonary alveolar proteinosis. Eur Respir J 2011;38:1361-1367.

10 Suzuki T, Trapnell BC: Pulmonary alveolar proteinosis syndrome. Clin Chest Med 2016; 37:431-440.

$\checkmark 11$ Ramirez J, Nyka W, McLaughlin J: Pulmonary alveolar proteinosis. Diagnostic technics and observations. N Engl J Med 1963;268: 165-171.

12 Ramirez J: Alveolar proteinosis: importance of pulmonary lavage. Am Rev Respir Dis 1971;103:666-678.

-13 Seymour JF, Presneill JJ, Schoch OD, Downie GH, Moore PE, Doyle IR, Vincent JM, Nakata K, Kitamura T, Langton D, Pain MC, Dunn AR: Therapeutic efficacy of granulo- cyte-macrophage colony-stimulating factor in patients with idiopathic acquired alveolar proteinosis. Am J Respir Crit Care Med 2001; 163:524-531.

14 Campo I, Kadija Z, Mariani F, Paracchini E, Rodi G, Mojoli F, Braschi A, Luisetti M: Pulmonary alveolar proteinosis: diagnostic and therapeutic challenges. Multidiscip Respir Med 2012;7:4.

15 Abdelmalak BB, Khanna AK, Culver DA, Popovich MJ: Therapeutic whole-lung lavage for pulmonary alveolar proteinosis: a procedural update. J Bronchology Interv Pulmonol 2015;22:251-258.

16 Froudarakis ME, Koutsopoulos A, Mihailidou HP: Total lung lavage by awake flexible fiberoptic bronchoscope in a 13-year-old girl with pulmonary alveolar proteinosis. Respir Med 2007;101:366-369.

17 de Blic J: Pulmonary alveolar proteinosis in children. Paediatr Respir Rev 2004;5:316-322.

18 Albafouille V, Sayegh N, De Coudenhove S, Scheinmann P, De Blic J, Mamou-Mani T, Hassine A, Jaubert F, Brunelle F: CT scan patterns of pulmonary alveolar proteinosis in children. Pediatr Radiol 1999;29:147-152.

19 Campo I, Luisetti M, Griese M, Trapnell BC, Bonella F, Grutters J, Nakata K, Van Moorsel $\mathrm{CH}$, Costabel U, Cottin V, Ichiwata $\mathrm{T}$, Inoue Y, Braschi A, Bonizzoni G, Iotti GA, Tinelli C, Rodi G: Whole lung lavage therapy for pulmonary alveolar proteinosis: a global survey of current practices and procedures. Orphanet J Rare Dis 2016;11:115.

20 Campo I, Luisetti M, Griese M, Trapnell BC, Bonella F, Grutters JC, Nakata K, Van Moorsel CH, Costabel U, Cottin V, Ichiwata T, Inoue Y, Braschi A, Bonizzoni G, Iotti GA, Tinelli C, Rodi G: A global survey on whole lung lavage in pulmonary alveolar proteinosis. Chest 2016;150:251-253.

-21 Zhao YY, Huang H, Liu YZ, Song XY, Li S, Xu ZJ: Whole lung lavage treatment of Chinese patients with autoimmune pulmonary alveolar proteinosis: a retrospective long-term follow-up study. Chin Med J (Engl) 2015;128: 2714-2719.

22 Bonella F, Bauer PC, Griese M, Ohshimo S, Guzman J, Costabel U: Pulmonary alveolar proteinosis: new insights from a single-center cohort of 70 patients. Respir Med 2011;105: 1908-1916.

23 Xu Z, Jing J, Wang H, Xu F, Wang J: Pulmonary alveolar proteinosis in China: a systematic review of 241 cases. Respirology 2009;14: 761-766.

- 24 Inoue Y, Trapnell BC, Tazawa R, Arai T, Takada T, Hizawa N, Kasahara Y, Tatsumi K, Hojo M, Ichiwata T, Tanaka N, Yamaguchi E, Eda R, Oishi K, Tsuchihashi Y, Kaneko C, Nukiwa T, Sakatani M, Krischer JP, Nakata K: Characteristics of a large cohort of patients with autoimmune pulmonary alveolar proteinosis in Japan. Am J Respir Crit Care Med 2008; 177:752-762.

25 Akasaka K, Tanaka T, Kitamura N, Ohkouchi S, Tazawa R, Takada T, Ichiwata T, Yamaguchi E, Hirose M, Arai T, Nakano K, Nei T, Ishii $\mathrm{H}$, Handa T, Inoue Y, Nakata K: Outcome of corticosteroid administration in autoimmune pulmonary alveolar proteinosis: a retrospective cohort study. BMC Pulm Med 2015; $15: 88$.

26 Khan A, Agarwal R, Agarwal A: Effectiveness of granulocyte-macrophage colony-stimulating factor therapy in autoimmune pulmonary alveolar proteinosis: a meta-analysis of observational studies. Chest 2012;141:1273-1283.

27 Kavuru MS, Bonfield TL, Thomassen MJ: Plasmapheresis, GM-CSF, and alveolar proteinosis. Am J Respir Crit Care Med 2003;167: 1036.

28 Bonfield TL, Kavuru MS, Thomassen MJ: Anti-GM-CSF titer predicts response to GMCSF therapy in pulmonary alveolar proteinosis. Clin Immun 2002;105:342-350.

29 Crocker HL, Pfitzner J, Doyle IR, Hague WM, Smith BJ, Ruffin RE: Pulmonary alveolar proteinosis: two contrasting cases. Eur Respir J 2000;15:426-429.

30 Chaulagain CP, Pilichowska M, Brinckerhoff L, Tabba M, Erban JK: Secondary pulmonary alveolar proteinosis in hematologic malignancies. Hematol Oncol Stem Cell Ther 2014; 7:127-135.

31 Morgan C: The benefits of whole lung lavage in pulmonary alveolar proteinosis. Eur Respir J 2004;23:503-505. 